\title{
ICD-11 as a Paradigm Shift Phase in the Classification of Mental Disorders
}

\author{
МКБ-11 как этап смены парадигм в классификации психических расстройств \\ doi:10.17816/CP70
}

\author{
(C) Valery N. Krasnov \\ Moscow Research Institute of Psychiatry - a branch of the \\ V. Serbsky National Medical Research Centre of Psychiatry \\ and Narcology of the Ministry of Health of the Russian \\ Federation, Moscow, Russia
}

\author{
(C) Валерий Н. Краснов \\ Московский научно-исследовательский институт \\ психиатрии - филиал Национального медицинского \\ исследовательского чентра психиатрии и наркологии \\ им. В.П. Сербского Минздрава России, Москва, Россия
}

\section{Editorial comment:}

Professor Valery Krasnov was one of the international leaders in ICD-11 development from the very beginning of this process. Being a Director of the Moscow Research Institute of Psychiatry (at present: a branch of the V. Serbsky Federal Medical Research Centre of Psychiatry and Narcology of the Ministry of Health of the Russian Federation) and President of the Russian Society of Psychiatrists for many years, professor Krasnov was involved with the WHO working groups on ICD-10 revision. From 2014 to 2017, he was the Russian representative in the International Field Study Coordination Group and was a principal of the ICD-11 field studies in Russia.

\section{ABSTRACT}

Classifications of mental disorders change regularly. This fact requires analysis, taking into account changes in the epidemiological situation and changes in the organizational structure of mental health service, and development of its technical and human resources. The preliminary analysis of these changes presented in the article using the example of ICD-11 gives us reason to believe that they are almost unrelated to the diagnostic process improvement. On the contrary, each new classification is characterized by an increasing formalization and simplification of the criteria for separate clinical forms. The inevitable losses of clinical accuracy in psychopathological assessment of disorder are compensated for increasing opportunities to deliver care to a significantly greater number of patients.

\section{АННОТАЦИЯ}

Классификации психических расстройств меняются регулярно. Этот факт требует анализа с учетом изменений эпидемиологической ситуации и изменений организационной структуры психиатрической помощи, развития ее технических и кадровых ресурсов. Представленный в статье предварительный анализ этих изменений на примере ICD-11 дает основания считать, что они почти не связаны с совершенствованием диагностического процесса. Напротив, каждая новая классификация характеризуется все большей формализацией и упрощением критериев отдельных клинических форм. Неизбежные потери точности психопатологической оценки болезненного состояния компенсируются расширяющимися возможностями оказания помощи значительно большему числу больных.

Keywords: classifications of mental disorders; ICD-11; paradigm shift

Keywords: классификация психических расстройств; ICD-11; смена парадигм 
Each epoch brings significant changes to medicine, including psychiatry. The following major changes have taken place in psychiatry in recent decades:

1. Major epidemiological studies indicate a consistent increase in both the incidence and prevalence of mental disorders, as well as mental health issues, often fraught with mental disorders themselves. Non-psychotic disorders such as depressive, anxiety, adjustment or stress-related disorders and pathological addictions are predominantly intended.

2. Comorbid conditions such as a combination of mental disorders and somatic or neurological diseases have become an important medical challenge.

3. Changes have been made to the institutional structure of psychiatric care: in particular, the expansion of outpatient forms of care while reducing the extent of inpatient care, and increasingly frequent inclusion of psychiatric departments in the structure of large general hospitals.

4. Development of a multi-professional model of mental health care has facilitated the participation of clinical psychologists and specialists in occupational therapy and social work etc.

5. There has been a shift towards delegation of authority to diagnose and provide treatment for non-psychotic, uncomplicated forms of mental disorders (in particular, mild depression and adjustment disorders without an obvious risk of suicidal or aggressive behaviour) to primary care physicians whose patients can access an appropriate care on an outpatient basis. These specialists are a common medical category in healthcare provision in most countries. As a rule, they have basic training in psychiatry, including knowledge of psychopharmacotherapy and the fundamentals of psychotherapy. They perform an important function as the "first filter" for identifying mental disorders and their differentiation, with referral of all patients with psychotic disorders (as well as diagnostically and therapeutically difficult cases) to psychiatric institutions.*
It was these particular changes, rather than advances in science or our growing knowledge about the complex nature of mental disorders and their connections with other medical issues, that influenced the radical turn from the ICD-9 classification ${ }^{1}$ and DSM-IV classification ${ }^{2}$ (which were based on scientific systematics, with their taxonomic rigour and consistency, and on the application of more or less homogeneous criteria for categorizing disorders) towards more utilitarian (and therefore simplified and eclectic) principles of diagnosis in the latest DSM-5 classification, ${ }^{3}$ and the following (with some minor changes) ICD-11 project. $^{4}$

Given this paradigm shift in understanding and formation of classification, ICD-10 has fulfilled a milestone preparatory role..$^{5}$ It has already declared the atheoreticism of the classification to be a rejection of any "ideology", primarily from psychoanalytic, psychodynamic concepts and, at the same time, from the nosological system in favour of a syndromological differentiation of clinical forms of mental pathology. Moreover, syndromes (in classical psychopathology, hierarchically organized interrelated disorders, as well as possible protective, "hypercompensatory" formations) were often distinguished as symptom complexes, i.e., combinations of symptoms occurring simultaneously, which can be actually heterogeneous when traced over time.

Of course, in contrast to a constantly improving framework as an orderly generalization of scientific knowledge and new facts, classification is the essence of a consensus document. It reflects different expert opinions and different influences - not only clinical but also cultural, legal and organizational. The latest DSM-5 classification and the ICD-11 project demonstrate clear tendencies towards simplification of diagnostic categories and, in addition, the inclusion of separate symptom complexes and even symptoms (most often heterogeneous in nature) in clinical forms. These are, for example, hoarding (excessive collecting of unnecessary things) or excoriation disorder (pathological skin picking). The named classifications are based on explicit diagnostic principles, supported by obvious, explicit manifestations, mainly behavioural.

* Unfortunately, there is still no government programme for the training of primary care physicians in Russia. Therefore, all activities delivering care to inpatients and outpatients with any mental disorders are legally assigned to psychiatrists. 
Eliminating types of schizophrenia and reducing them to a single form, regardless of the syndromes' structure, a disease's course and outcomes, is the most illustrative example of clinically controversial and even challenging (in relation to the choice of therapy) simplification. However, the ICD-11 project already lists the course options: indication of a currently symptomatic episode; an episode in partial remission; an episode in full remission; or the possibility of a continuous course. Besides, additional qualifiers on symptomatic manifestations presented in different domens can catch an impact and proportion of positive, negative, depressive or manic, psychomotor and cognitive symptoms. Perhaps these are the only guidelines regarding choice of therapy and rehabilitation measures. In general, the new classification does not include prognostic and therapeutic indications.

Psychiatric phenomenology in its classical European tradition (as an empathic, insightful understanding of the patient's experience, in accordance with the views of $\mathrm{K}$. Jaspers ${ }^{6}$ ) is almost completely replaced by formal registration of the presenting symptoms. In this regard, it is worth recalling that back in 2007, one of the leaders of the American Psychiatric Association, N. Andreasen, published an article which caused a wide response, entitled "DSM and the death of phenomenology in America". 7 The author suggested referring to the vast experience of European psychiatry, believing that simplistic tendencies in US clinical psychiatry are flawed. However, it is apparent that her words have not been heeded. Meanwhile, phenomenological analysis particularly allows psychiatrists to not only reveal the nuances of patients' painful experience but also find opportunities for patients to resist the disease, preserving personal qualities and values that help build a partnership with the patient - the so-called therapeutic alliance.

It seems that the modern classification is addressed mainly to primary care physicians, as well as clinical psychologists involved in modern multi-professional work with patients. The psychiatrist is left with a more complex and responsible function associated with the treatment of "difficult" patients, not only with psychotic forms and socially dangerous tendencies, but also with the phenomena of therapeutic resistance, which, in recent years, have become an increasingly frequent therapeutic challenge.

Some specialists, trying to create new classifications for the future, offer speculative projects that have already been completely detached from clinical practice. So, in recent publications, the so-called hierarchical taxonomy of psychopathology (HiTOP) is discussed. This represents a multi-level structure. The general factor, which unites the largest number of correlated interrelated symptoms, is located at the upper level; below, there are multi-directional constructs of "internalization" and "externalization"; lower down, there are heterogeneous symptoms. ${ }^{8,9}$

ICD-11 looks more solid in contrast. It is quite useable to provide a statistical registration of nosographic units presenting in the classification. However, in real practical work, a psychiatrist of the European and Russian psychopathological tradition will certainly strive to reveal the vast array of clinical content available, based not on statistical diagnosis (as indicated in the patient's record) but rather on a proper individualized diagnosis in each specific case.

It should be noted that there are some positive trends outlined in the new classification. In particular, these relate to approximation, in some sections, to the building of a functional diagnosis. Particular attention is paid to the possibilities for social functioning before the disease, at different stages of its course and in remission, which represents the strongest aspect of the new classification.

Moreover, while the ICD-11 classification is in progress of translating into national languages, the additional codes and special comments that bring diagnostic categories closer to real practice can be used. This will also help to make the classification more suitable for educational activities.

Conflict of interests: Author declare no conflict of interest.

\section{Correspondence to:}

\section{Prof. Valery N. Krasnov, MD}

valery-krasnov@mail.ru

\section{For citation:}

Krasnov VN. ICD-11 as a paradigm shift phase in the classification of mental disorders. Consortium Psychiatricum. 2021;2(2):72-75. doi:10.17816/CP70 


\section{References}

1. World Health Organization. International statistical classification of diseases, injuries, and causes of death. $9^{\text {th }}$ revision. World Health Organization; 1979.

2. American Psychiatric Association. Diagnostic and statistical manual of mental disorders. 4rd ed. American Psychiatric Association; 1994.

3. American Psychiatric Association. Diagnostic and statistical of mental disorders. $5^{\text {th }}$ ed. American Psychiatric Association; 2013.

4. World Health Organization. ICD-11 guidelines. Published 2016. Accessed April 6, 2021. https://gcp.network/en/icd-11-guidelines

5. World Health Organization. The ICD-10 classification of mental and behavioural disorders: clinical descriptions and diagnostic guidelines. World Health Organization; 1992.
6. Jaspers K. Allgemeine Psychopathologie. Verlag von Julius Springer; 1913.

7. Andreasen NC. DSM and the death of phenomenology in america: an example of unintended consequences. Schizophr Bull. 2007;33(1):108-112. doi:10.1093/schbul/sbl054

8. Kotov R, Krueger RF, Watson D. A paradigm shift in psychiatric classification: the Hierarchical Taxonome of psychopathology (HiTOP). World Psychiatry. 2018;17(1):24-25. doi:10.1002/ wps.20478

9. Lahey BB, Moore TM, Kaczkurkin AN, Zald DH. Hierarchical models of psychopathology: empirical support, implications, and remaining issues. World Psychiatry. 2021;20(1):57-63. doi:10.1002/ wps. 20824 